\title{
COMPARISON OF SURROGATE AND SUBJECT REPORTS OF DIETARY PRACTICES, SMOKING HABITS AND WEIGHT AMONG MARRIED COUPLES IN THE TECUMSEH DIET METHODOLOGY STUDY
}

\author{
Helen L. Metzner, ${ }^{1,2}$ Donald E. Lamphiear, ${ }^{1}$ Frances E. Thompson, ${ }^{1 *}$ \\ MARY S. OH' ${ }^{1}$ and VICTOR M. HAWTHORNE ${ }^{1}$ \\ 'Department of Epidemiology and ${ }^{2}$ Human Nutrition Program, School of Public Health, \\ University of Michigan, Ann Arbor, MI 48109, U.S.A.
}

(Received in revised form 24 March 1988)

\begin{abstract}
Agreement between surrogate and subject reports of current food frequencies and other eating habits, smoking behavior and weight was assessed in 1982-1983 for 180 husbands and wives, aged 45 through 64 years. Agreement was measured by per cent exact agreement and weighted kappa for frequencies of 30 itemized foods or food groups, and for surrogate- and subject-based quintiles of frequencies of eight broad food groups and of vitamin $\mathrm{A}$ and $\mathrm{C}$ consumption indexes. Surrogate and subject mean frequencies were generally similar, but at the individual level of analysis, agreement varied widely. Agreement was greatest, among the food items and groups, for alcoholic beverages, and among the other items, for smoking status. Extreme misclassification by quintile was very small, but only $40 \%$ of persons self-classified in either extreme quintile were similarly classified by their spouses. This level of misclassification may result in the dilution of real relationships between diet and health.
\end{abstract}

Diet Drinking Smoking Vitamin A Epidemiologic methods

\section{INTRODUCTION}

Retrospective epidemiologic investigations often must rely on data about behavior, such as smoking and eating habits, that are provided by surrogate reporters, usually spouses or other close relatives; the subjects may be dead or too ill to answer questions. In analyses, some investigators combine information provided by surrogates with that provided by the subjects themselves [1], thus implicitly assuming that information from the two sources are comparable. It would seem important to test the validity of this assumption by assessing the degree of comparability for various kinds of information provided by surrogates.

Problems associated with the use of surrogate responses include possible misclassification of

*Presently at: Division of Nutritional Sciences, Cornell University, Ithaca, NY 14853, U.S.A.

This work was supported by National Cancer Institute Grant R18 27979. subjects and bias related to mortality or presence of disease [2]. Research on the agreement between surrogate and index answers has been reported by Kolonel et al. [3], Marshall $e t$ al. [4] and Lerchen and Samet [5] for wives as surrogate reporters for their husbands, and by Humble et al. [6] for both husbands and wives as surrogate reporters for their spouses.

The Tecumseh Diet Methodology Study provided an opportunity to study agreement between subject and surrogate reports among 180 husbands and wives who were subjects and surrogate reporters for their spouses. In the analyses presented here, the major focus is on degree of agreement in reporting frequencies of individual foods and food groups. Data are also presented on degree of agreement in reports of other variables of epidemiologic interest, i.e. perception of change in eating patterns, current weight, cigarette smoking behavior, current employment status and occupation. 


\section{MATERIALS AND METHODS}

\section{Study population}

The respondents were long-time participants in the Tecumseh Community Health Study, an on-going, longitudinal, epidemiological study of chronic disease in a total community [7]. The men and women who provided the data for this report were part of the cohort of 1387 individuals in the 1967-1969 round of interviews and medical examinations who were included in the 1982-1983 Diet Methodology Study. To be eligible for the Diet Methodology Study, respondents had to be 45-65 years of age in 1982-1983 and to have participated in the dietary component of the 1967-1969 study. The overall purpose and design of the Diet Methodology Study and the attrition and participation rates of the eligible cohort have been reported earlier [8].

The surrogates in this study were those participants in a randomly selected subgroup in the Diet Methodology Study who had a spouse also in the current study. Ninety-four of the 180 respondents belonged to couples in which both members were subjects and surrogates for their spouses. Eighty-six respondents were included in this study only as surrogates for their spouses who, in turn, participated only as subjects.

The demographic characteristics of the surrogate respondents (86 men and 94 women) resembled those of the entire Diet Study population: $44 \%$ were in the younger decade, that is, $45-54$ years of age; $28 \%$ had less than 12 years of formal education, $55 \%$ had completed high school, and $17 \%$ had one or more years of college; one-third of the sample were in each of the following categories, white collar occupations, blue collar occupations, and not currently employed.

\section{Interview procedure}

Surrogate respondents usually provided data for this report in two interviews. In the first interview, they provided the following information about themselves: demographic data, current food frequency use by a selfadministered food frequency card sort, smoking patterns, weight and perception of change in diet patterns. In the second interview, which usually followed the first by a week or two, they provided the same kind of information for their spouses.

\section{Variables}

Surrogate respondents were asked about their spouses' current diet using the same procedures that they and their spouses used for reporting about themselves [8]. In the surrogate study, a subset of 30 of the 83 food cards used in the larger study to depict total diet were used to describe each spouse's diet. The foods were sorted into the same eight frequency categories: never or almost never, once or a few times a year, about one to three times a month, about once a week, about twice a week, about three to five times a week, about once a day, and about twice a day or more often. Additionally, questions about the daily use of coffee and tea were also asked. Portion size was not assessed.

Twenty-four of the 30 foods (Table 1) in the sort procedure were combined into eight food groups. For each respondent, frequency of consumption per week of the eight food groups was obtained by summing the midpoints of the frequency ranges he or she reported for each food in the group. For example, if a food group had three constituent foods (as did dairy products in Table 2), and each was reported as having been consumed three to five times a week, the frequency for that group was computed as 12 times per week, by summing the midpoint of four over the three constituent foods.

Vitamin $\mathrm{A}$ and $\mathrm{C}$ indexes were calculated from foods contributing substantial amounts of these vitamins to the U.S. diet, 25 foods for vitamin A and 16 foods for vitamin C. A detailed explanation of the method of calculating the vitamin indexes for the group of foods in the larger study has been reported [8]. Briefly, the value of each vitamin index for the individual was calculated by first obtaining the product of the midpoint of the frequency range he or she reported for a food item times the usual vitamin value for that item, and then summing the products over all the food items in the index. For respondents in this study, the mean vitamin A index value from the 30 -food-item set was $84 \%$ of the mean vitamin $A$ value from the larger set of 83 foods; the mean vitamin $C$ value from the 30 -food-item set was $83 \%$ cent of that vitamin's mean value from the larger set of foods.

Subject respondents also provided data for themselves and surrogate respondents provided data for their spouses on: demographic variables; weight; smoking habits; whether they 
added salt at the table; ate the fat on meat; changed their eating patterns in the past 15 years; and how many meals they and their spouses usually ate together.

All respondents were asked for their own abbreviated health histories consisting of questions about current use of special diets and the onset and treatment of nine chronic conditions related to diet. In the analysis, the nine chronic conditions were combined into four categories: cardiovascular conditions, including heart attack, other heart trouble and hypertension; digestive trouble, including stomach or duodenal ulcer, gallbladder trouble and intestinal or bowel trouble; endocrine conditions, including diabetes and thyroid trouble; and tumor.

\section{Statistical methods}

Agreement on individual foods and other individual items. Agreement between the subject's self report and the surrogate's report was measured for each of the 30 foods by the weighted kappa statistic [9], per cent exact agreement, and per cent agreement within one category. Kappa incorporates an adjustment for the number of agreements expected by chance; weighted kappa takes into account the degree of disagreement in equal-interval ordered data. Fleiss and Cohen [9] have shown that with a large number of cases, weighted kappa is equivalent to the intraclass correlation coefficient. The rationale for use of the weighted kappa with the present data, the method of computation and the interpretation of the kappa statistic have been described elsewhere [8]. Agreement between the subject and surrogate reports for other variables was measured by per cent agreement.

Mean frequencies per week obtained from the subjects' and surrogates' reports were also compared. Because the distributions for the foods were skewed, $\log$ transformations were used in the calculations of the paired $t$-test. For presentation in this report, the values are shown in the original units.

Agreement on food groups. The distributions of weekly frequencies for six of the eight food groups were also skewed; dairy products and fats and oils added at the table were exceptions. Log transformations of the skewed variables were used in analysis but results from log transformed values have been expressed in the original units. Subject and surrogate means were compared by the paired $t$-test and confidence intervals for the mean difference were computed at the $95 \%$ level. Subject and surrogate weekly frequencies for food groups were also categorized into quintiles and degree of agreement determined by weighted kappa, per cent exact agreement, per cent agreement within one category and per cent extreme disagreement.

\section{RESULTS}

\section{Agreement on individual foods}

Agreement varied widely on the individual foods and to some extent as to whether the surrogate was a wife or husband. Agreement on frequency was greatest for all surrogate-spouse pairs for the three types of alcoholic beverages, beer, wine and other alcohol (kappas ranging from 0.70 to 0.92 and per cent exact agreement from 56 to 74), and was smallest for a mixed vegetables group including, among others, carrots, peas and beets, and for butter added to foods at the table (kappas ranging from 0.19 to 0.29 and per cent exact agreement 21-35). Agreement was also small (kappas less than 0.30), when wives were surrogates, for margarine added to food at the table and beef, and when husbands were surrogates, salad dressings, cheese and pie (Table 1).

Agreement on number of cups of coffee and tea per day was also high (data not shown).

Mean frequencies per week from surrogate reports were generally similar to those from subject reports and showed no consistent pattern of over- or under-reporting (Table 1). There were only three differences in untransformed mean frequencies per week reported by surrogates and subjects that were as large as one time per week. When frequencies were log transformed for testing for statistical significance, the following three food items showed statistical significance $(p<0.05)$ for both sets of surrogates: cake, the vegetable group including beets, carrots and peas, and margarine added to food at the table.

Wife-surrogates showed somewhat better agreement with their spouses than did husbandsurrogates; the average kappa for the $\mathbf{3 0}$ food frequencies was 0.53 for wife-surrogates and 0.42 for husband-surrogates. For 24 out of 30 foods, the wife-surrogates' kappas were larger than those of husband-surrogates $(p<0.01$, sign test), and nine of the differences between these kappas were as large as $\mathbf{0 . 2 0}$. 


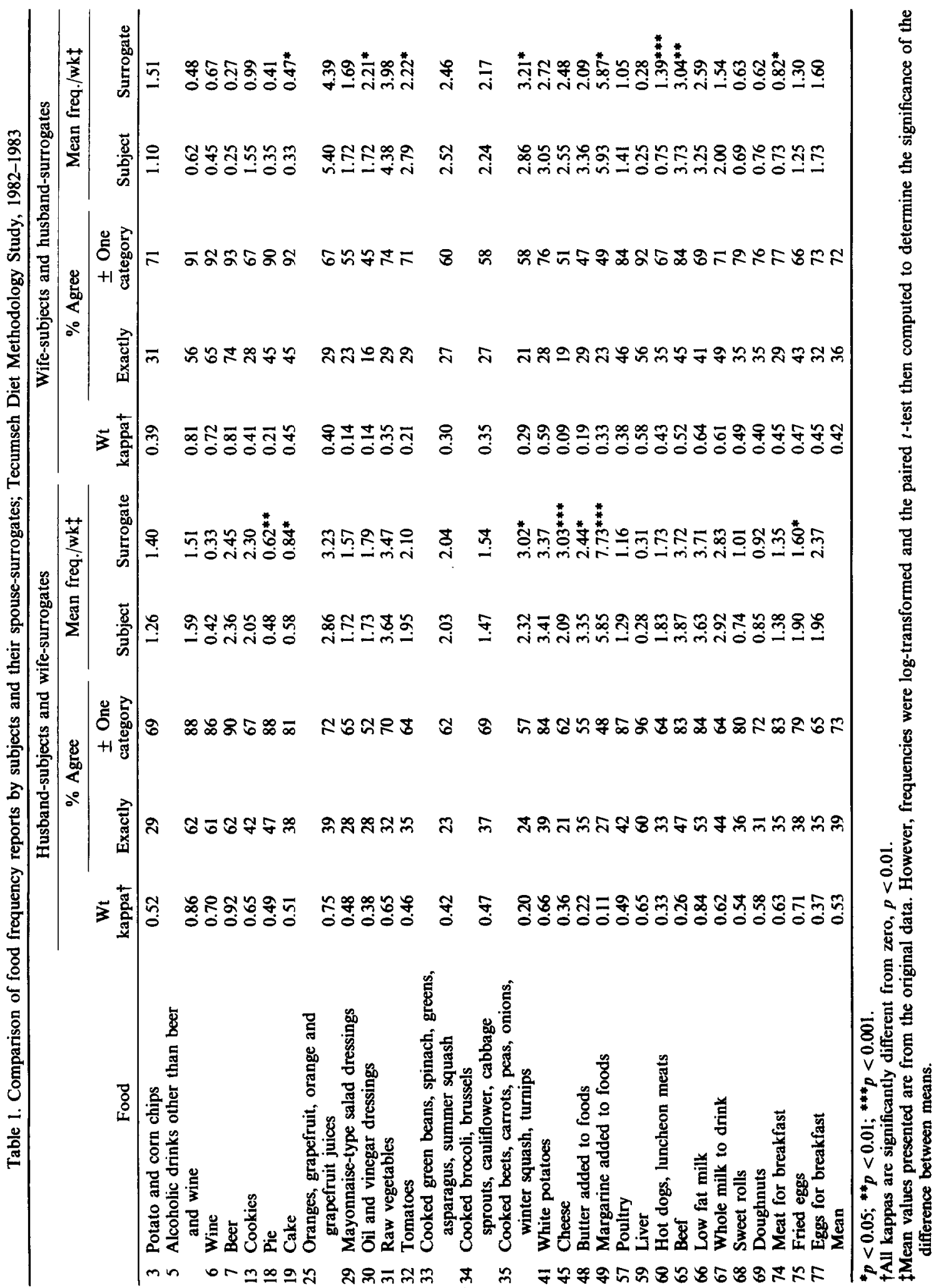


Table 2. Comparison of reports of frequency per week for food groups and for amounts of vitamins $\mathrm{A}$ and $\mathrm{C}$ per day by subjects and their spouse-surrogates; Tecumseh Diet Methodology Study, 1982-1983

\begin{tabular}{|c|c|c|c|c|c|c|}
\hline \multirow[b]{2}{*}{ Food group* } & \multicolumn{3}{|c|}{$\begin{array}{l}\text { Husband-subjects and wifc-surrogates } \\
\qquad(N=94)\end{array}$} & \multicolumn{3}{|c|}{$\begin{array}{l}\text { Wife-subjects and husband-surrogates } \\
\qquad(N=86)\end{array}$} \\
\hline & $\begin{array}{l}\text { Subjects' } \\
\text { mean }\end{array}$ & $\begin{array}{c}\text { Difference } \dagger \\
\text { (surrogate- } \\
\text { subject) }\end{array}$ & $\begin{array}{c}95 \% \dagger \\
\text { confidence } \\
\text { interval }\end{array}$ & $\begin{array}{c}\text { Subjects' } \\
\text { mean }\end{array}$ & $\begin{array}{c}\text { Difference } \dagger \\
\text { (surrogate- } \\
\text { subject) }\end{array}$ & $\begin{array}{c}95 \% \dagger \\
\text { confidence } \\
\text { interval }\end{array}$ \\
\hline & $\begin{array}{l}\text { Frequency } \\
\text { per week }\end{array}$ & & & & & \\
\hline Poultry (57) & 0.93 & -0.01 & $-0.13,0.14$ & 1.01 & -0.13 & $-0.25,0.02$ \\
\hline Meat $(59,60,65,74)$ & 6.46 & -0.14 & $-0.90,0.73$ & 4.60 & 0.15 & $-0.39,0.77$ \\
\hline Dairy $(66,67,45)$ & 8.64 & 0.93 & $-0.35,2.22$ & 7.80 & -1.19 & $-2.42,0.04$ \\
\hline Citrus (25) & 1.35 & 0.00 & $-0.26,0.32$ & 3.40 & -0.68 & $-1.32,0.14$ \\
\hline \multicolumn{7}{|l|}{ Vegetables } \\
\hline$(31,32,33,34,35)$ & 8.78 & 1.07 & $-0.37,2.76$ & 12.02 & -0.19 & $-1.96,1.87$ \\
\hline \multicolumn{7}{|l|}{ Fats and oils added to } \\
\hline foods $(29,30,48,49)$ & 12.65 & 0.89 & $-1.00,2.78$ & 12.73 & -0.87 & $-3.15,1.40$ \\
\hline Sweets $(13,18,19)$ & 1.72 & 0.24 & $-0.11,0.68$ & 1.40 & -0.13 & $-0.38,0.18$ \\
\hline \multirow[t]{2}{*}{ Alcohol $(5,6,7)$} & 1.06 & -0.06 & $-0.19,0.08$ & 0.39 & 0.03 & $-0.05,0.11$ \\
\hline & $\begin{array}{l}\text { Amounts } \\
\text { per day }\end{array}$ & & & & & \\
\hline Vitamins $A$ index (IU) & 5793 & 878 & 185,1651 & 6344 & -77 & $-796,735$ \\
\hline Vitamin $\mathrm{C}$ index (mg) & 65.4 & 3.68 & $-3.85,12.14$ & 98.9 & 7.88 & $-21.74,8.47$ \\
\hline
\end{tabular}

*The number(s) in parentheses refers to the food item in Table 1.

†Statistical tests were done on log transformed data for all food groups except dairy and fats and oils. The values in the table, however, are expressed in the original units.

\section{Agreement on food groups}

Only one difference in mean intake from 20 surrogate-sex-specific food group comparisons, as shown in Table 2, was statistically significant $(p<0.05)$; wife-surrogates tended to overreport their husbands' vitamin A intake. Spearman's rank order correlations between index and surrogate reports for the food groups resulted in values (not shown) close to the kappa values for quintile agreement shown in Table 3 and described below.

Kappas for agreement of quintile ranks of surrogate and subject reports (Table 3 ) ranged from low values for meat from wife-surrogates $(0.13)$ and for fats and oils from both wife- and husband-surrogates $(0.24,0.19)$ to high values for alcohol from both wife- and husbandsurrogates $(0.93,0.80)$. Kappas from wifesurrogates were greater than kappas from husband-surrogates for eight of the ten food groups, and greater by 0.20 or more for four of the groups: dairy, citrus, sweets, and vitamin C.

Per cent exact agreement ranged from a low of 21 for vegetables to a high of 76 for alcoholic beverages, both reported by wife-surrogates. The alcohol group showed the highest agreement for both sexes; per cent agreement within one quintile category was almost perfect for this group. Meat, vegetables, fats and oils added to foods and vitamin A showed the smallest values for per cent exact agreement for wife-surrogates, less than 30, and fats and oils and vitamin C showed the same low level of exact agreement for husband-surrogates.

A measure of extreme misclassification by surrogate reports is indicated in Table 3 by the per cent of subjects placed by surrogate reports in the fifth quintile when placed by self reports in the first, or placed in the first by surrogate reports when placed in the fifth by self reports. In general, these misclassification values were quite small; the largest was one value of $9 \%$. There was no extreme misclassification by wifesurrogates for five food groups nor by husbandsurrogates for three. The alcohol and dairy food groups showed no extreme misclassification by any surrogate.

Per cent agreement on variables other than specific foods

Subject and surrogate reports agreed extremely well for variables describing the subject's current employment (Table 4). Agreement was also very high for current smoking status, somewhat less for past smoking of cigars and pipes, and much less for number of cigarettes currently smoked. Agreement was moderate for the other variables.

Husband- and wife-surrogates generally showed about the same per cent of exact agreement with their spouses on these variables. Only one comparison was statistically significant 
Table 3. Agreement between subject and surrogate quintiles of food group frequencies and amounts of vitamins $A$ and C; Tecumseh Diet Methodology Study, 1982-1983

\begin{tabular}{|c|c|c|c|c|c|c|c|c|}
\hline \multirow[b]{3}{*}{ Food group* } & \multicolumn{4}{|c|}{ Husband-subjects and wife-surrogates } & \multicolumn{4}{|c|}{ Wife-subjects and husband-surrogates } \\
\hline & \multirow[b]{2}{*}{$\begin{array}{c}\text { Wt } \\
\text { kappa }\end{array}$} & \multicolumn{2}{|c|}{$\%$ Agree } & \multirow{2}{*}{$\begin{array}{c}\text { Disagreet } \\
\text { extremely } \\
\%\end{array}$} & \multirow[b]{2}{*}{$\begin{array}{c}\mathbf{W t} \\
\text { kappa }\end{array}$} & \multicolumn{2}{|c|}{$\%$ Agree } & \multirow{2}{*}{$\begin{array}{c}\text { Disagree } \\
\text { extremely } \\
\%\end{array}$} \\
\hline & & Exactly & $\begin{array}{c} \pm \text { One } \\
\text { category }\end{array}$ & & & Exactly & $\begin{array}{c} \pm \text { One } \\
\text { category }\end{array}$ & \\
\hline Poultry & 0.49 & 44 & 89 & 1 & 0.42 & 46 & 84 & 0 \\
\hline Meat & 0.13 & 29 & 63 & 9 & 0.45 & 42 & 71 & 1 \\
\hline Dairy & 0.64 & 40 & 78 & 0 & 0.41 & 35 & 71 & 0 \\
\hline Citrus & 0.75 & 50 & 83 & 0 & 0.37 & 42 & 72 & 7 \\
\hline Vegetables & 0.34 & 21 & 65 & 5 & 0.29 & 30 & 60 & 2 \\
\hline Fats and oils & 0.24 & 29 & 65 & 4 & 0.19 & 22 & 57 & 6 \\
\hline Sweets & 0.65 & 47 & 81 & 1 & 0.43 & 33 & 74 & 2 \\
\hline Alcohol & 0.93 & 76 & 97 & 0 & 0.80 & 63 & 94 & $\overline{0}$ \\
\hline Vitamin $\mathbf{A}$ index & 0.37 & 27 & 64 & 0 & 0.37 & 39 & 68 & 4 \\
\hline Vitamin $C$ index & 0.62 & 36 & 78 & 0 & 0.34 & 28 & 71 & 4 \\
\hline
\end{tabular}

*Constituent food items for the first eight food groups are listed in Table 2.

+Per cent of total number of respondents classified in quintile one by subject and in quintile five by surrogate, and vice versa.

Table 4. Per cent exact agreement between subject and surrogate reports for selected characteristics and behavior patterns of the subjects; Tecumseh Diet Methodology Study, 1982-1983

\begin{tabular}{|c|c|c|c|c|c|c|}
\hline \multirow[b]{3}{*}{ Subjects' characteristic or behavior pattern } & \multicolumn{3}{|c|}{$\begin{array}{l}\text { Husband-subjects } \\
\text { and wife-surrogates }\end{array}$} & \multicolumn{3}{|c|}{$\begin{array}{l}\text { Wife-subjects and } \\
\text { husband-surrogates }\end{array}$} \\
\hline & \multirow[b]{2}{*}{$N^{*}$} & \multicolumn{2}{|c|}{ Agree exactly } & \multirow[b]{2}{*}{$N^{*}$} & \multicolumn{2}{|c|}{ Agree exactly } \\
\hline & & $n$ & $\%$ & & $n$ & $\%$ \\
\hline \multicolumn{7}{|l|}{ Employment } \\
\hline Currently working/not working & 94 & 92 & 98 & 86 & 85 & 99 \\
\hline If employed, current occupation & 74 & 72 & 97 & 49 & 45 & 92 \\
\hline \multicolumn{7}{|l|}{ Smoking } \\
\hline Ever/never smoked cigarettes & 94 & 90 & 96 & 85 & 84 & 99 \\
\hline smoking cigarettes & 72 & 70 & 97 & 36 & 35 & 97 \\
\hline If ex-smoker, number of cigarettes per day & & & & & & \\
\hline $\begin{array}{l}\text { usually smoked within five cigarettes } \\
\text { If current smoker, number of cigarettes per }\end{array}$ & 42 & 12 & 29 & 14 & 8 & 57 \\
\hline day within five cigarettes & 18 & 10 & 56 & 19 & 12 & 63 \\
\hline Ever/never smoked cigars & 91 & 73 & 80 & - & - & - \\
\hline $\begin{array}{l}\text { If ever smoked cigars, currently/not } \\
\text { currently smoking }\end{array}$ & 30 & 28 & 93 & - & - & - \\
\hline Ever/never smoked pipes & 91 & 73 & 80 & - & - & - \\
\hline $\begin{array}{l}\text { If ever smoked pipes, currently/not } \\
\text { currently smoking }\end{array}$ & 38 & 38 & 100 & - & - & - \\
\hline \multicolumn{7}{|l|}{ Diet patterns } \\
\hline $\begin{array}{l}\text { Adds/does not add salt to food after } \\
\text { it is served } \\
\text { If salt added, adds salt before or after }\end{array}$ & 74 & 62 & 84 & 70 & 57 & 81 \\
\hline 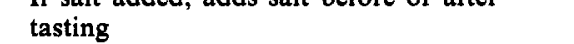 & 27 & 17 & 63 & 18 & 11 & 61 \\
\hline If salt added, relative amount & 27 & 15 & 56 & 18 & 11 & 61 \\
\hline Eats no fat on meat, some or all the fat & .75 & 43 & 57 & 49 & 46 & 67 \\
\hline \multicolumn{7}{|l|}{$\begin{array}{l}\text { Perception of change in diet patterns over } \\
\text { last } 15 \text { years }\end{array}$} \\
\hline $\begin{array}{l}\text { Change/no change in size of portions } \\
\text { Change/no change in frequency of eating }\end{array}$ & 93 & 64 & 69 & 83 & 51 & 61 \\
\hline occasions & 91 & 65 & 71 & 75 & 41 & 55 \\
\hline Change/no change in kinds of foods eaten & 82 & 47 & 57 & 73 & 47 & 64 \\
\hline \multicolumn{7}{|l|}{ Current weight } \\
\hline Within $5 \mathrm{lb}$ & 91 & 72 & 79 & 69 & 47 & 68 \\
\hline
\end{tabular}

"Numbers of cases on which per cents were calculated vary because of differing non-response rates, by subjects or surrogates, because agreement was calculated for subgroups as indicated, and because the diet pattern questions were only asked of a subset of subjects. 
using the chi-squared test; more wife- than husband-surrogates agreed with their spouses on whether the frequency of the subject's eating occasions had changed since $1967(p<0.05)$.

\section{DISCUSSION}

The comparative homogeneity of the study sample and the close timing of the subject-surrogate intervicws would scem to be especially favorable for subject-surrogate agreement. The group was composed of persons aged 45-64 at time of current interview, who were in marriages of long duration and of predominantly of north European descent. All respondents were experienced in answering health history and behavior questions, having been participants in the Tecumseh Community Health Study for 15 years or more. Subjects and surrogates were usually interviewed within 2 weeks of one another. By contrast, in most other studies respondents were selected on the basis of health status (or as controls) and their surrogates sometimes included individuals other than spouses [4-6,10,11].

One of several methods that measure correspondence between index and spouse-surrogate reports compares the mean frequencies of subject and surrogate reports of consumption. Several studies [3-6], including ours, have found close agreement on mean frequencies for most individual foods and food groups. These findings suggest that if the analysis calls only for comparing mean frequencies for groups of subjects, as in a comparison of case and control group values, surrogate reports may be almost as useful as subject reports $[4,12]$.

Methods that measure agreement on individual foods by subject-surrogate pair have shown less reassuring results. When comparisons were made by frequency categories, per cent exact agreement and kappa varied greatly among individual foods. In our study, which used eight frequency categories, per cent exact agreement values, ranging from 16 to 74 , were generally lower than those reported by other studies which used only four or five categories [3-6]. High per cent agreement due to chance is to be expected when fewer categories are used and for foods that are used very frequently or infrequently. Kappa values, which measure agreement beyond chance, are less sensitive to the number of categories. Direct comparisons between our weighted kappa and the unweighted kappas reported by other studies [4-6] are not appropriate because weighted kappas yield higher values when disagreements are largely between adjacent categories.

Some understanding of the reasons for the wide variation in agreement among foods would help in the planning of epidemiologic investigations of diet and the design of interviews. Which foods, if any, are more reliably reported consistently across studies? Can this relationship be explained?

The highest agreement for intake items was found, in this study and others $[3,4]$, for alcohol consumption. There is a strong social norm attached to alcohol consumption which may result in heightened awareness of this behavior. Subject and surrogate may both report values closer to behavior or to their shared perception of the social norm. The shared perception may or may not reflect actual behavior. The close agreement on other beverage consumption may result from a strong, almost ritual, pattern of daily consumption of these items, especially coffee and tea, and the fact that these beverages were perceived to have few alternatives.

Agreement between subjects and surrogates on frequency of consumption of other food groups show little consistency across studies. In our study, poor agreement for the items subsumed under fats and oils added at the table and vegetables may have been due to deficiencies attributable to the questionnaire. Lack of emphasis on distinguishing between margarine and butter when the term butter is commonly used to refer to both fats may have led to the poor agreement for those foods. The groups of various vegetables that we used for four of the five vegetable items probably did not correspond to the way people either select and eat their vegetables or think about how they eat them. Consequently, these items may have presented respondents with very difficult tasks in the estimation of their average frequencies.

Poor agreement may have also resulted for foods that subjects ate at times or in situations that their spouses could not directly observe. These foods include those that may have been eaten for lunch, such as lunch meats and beef (in hamburgers, possibly) by husband-subjects, and foods that are added at the table by the subject, such as margarine, butter, and salad dressings. A statistical analysis tested whether agreement on four food items in this group of foods was better when subjects and surrogates shared three meals than when fewer meals were shared. Agreement for husband-surrogate 
reports showed significant improvement in kappas, when three meals were shared, for butter and margarine, and noticeable but not statistically significant improvement for cheese. Agreement for lunch meats was also tested, although this item was not originally in as poor agreement by husband-surrogates as were the other tested items; even so, husbands sharing three meals with their wives showed improved agreement, though not significantly so. Agreement in wife-surrogate reports showed no significant improvement for these foods when three meals were shared. These particular analyses would seem to indicate that husbandsurrogate agreement would be better among those husbands who are in situations where they can observe more of their wives' eating patterns.

At the individual level, in contrast, analysis of food groups showed a wide range in the degree of agreement. Agreement between subject- and surrogate-based quintiles for food groups as measured by kappa and per cent exact agreement did not show much improvement over agreement found for individual foods. Wifesurrogates tended to be better reporters for their spouses than did husband-surrogates; however all surrogate reporting about fats and oils, vegetables and vitamin $\mathrm{A}$ was poor. Wifesurrogates had very poor agreement with their husbands for meats. Per cent agreement and kappas for food group quintiles in this study were lower than mean per cent agreement and kappas for food group frequencies reported by Herrmann [11]. In that study, husbandsurrogates seemed to agree better with their spouses than did wife-surrogates.

When misclassification of those in the first and fifth quintiles by self-report was considered, very small percentages of all subjects were extremely misclassified by their spouses for any one food group; the largest was $9 \%$. Another way to look at proportions misclassified is to confine the denominator to those classified only in the first and fifth quintiles by self-report and compute the proportion similarly classified by surrogate-report. Reports by wife-surrogates similarly classified from 80 to $95 \%$ of those husbands who were in the first and fifth quintiles by self-report for alcohol and citrus (data not shown). However, for the remaining eight food groups, including the two vitamins, wifesurrogates classified in the first and fifth quintiles an average of only $41 \%$ of husbands so classified by their own report. Husbandsurrogates similarly classified $86 \%$ of wives in the extreme categories for alcohol, but did not do as well as wife-surrogates for citrus. For the nine food groups excluding alcohol, husbandsurrogates classified in the two extreme categories an average of only $39 \%$ of their wives so classified by self-report. This level of misclassification would severely dilute any real association between diet and outcome.

Congruent with the findings from other studies $[3,5,10,11]$, subject-surrogate agreement was high for smoking status and other easily observed behavior that can be dichotomously classified. However, subject-surrogate agreement was poorer for details such as numbers of cigarettes smoked, and salt and fat consumption at the table.

Underlying the comparisons in this and similar studies is the assumption that subjects are better reporters of their own habits. Without independent data showing that surrogates, particularly wives, provide more valid information on consumption, it scems reasonable to proceed on the basis that, in general, subjects know and are the best reporters of what they eat. In the absence of self-reporters, however, spouse-surrogates seem to be able to provide reasonably similar data on alcohol, coffee and tea consumption. Spouse-surrogates' ability to provide information on other foods or food groups similar to what would be provided by their spouses appears to depend somewhat on how often they can observe what their spouses eat.

Although surrogate reports of dietary patterns and other behavior are not the same as self-reports, they have considerable value as the only source of information in many studies. Investigators may assume that surrogates will rarely misclassify subjects into extremely opposite categories, however surrogate reports will result in the more central classification of a fairly high proportion of subjects with high or low dietary exposures by self-report. Moderate relationships, thus, may be missed entirely, and relationships that appear moderate may in fact be strong. Nevertheless in studies with sample size large enough to show statistically significant differences between subgroups from the surrogate reports, effects of dietary differences should be demonstrable.

Acknowledgements-The authors wish to thank Frances A. Larkin for her nutritional advice. They also wish to acknowledge the contributions of Grace Lim to the collection and processing of the nutritional data; Catherine Meade to the design of the questionnaire and supervision of 
data processing; Alice Exelby for supervision of field work; and Mark A. Archer for computer programming

\section{REFERENCES}

1. Ziegler RG, Mason TJ, Stemhagen A, et al. Carotenoid intake, vegetables, and the risk of lung cancer among white men in New Jersey. Am J Epidemiol 1986; 123: 1080-1093.

2. Gordis L. Should dead cases be matched to dead controls? Am J Epidemiol 1982; 115: 1-5.

3. Kolonel LN, Hirohata T, Nomura AMY. Adequacy of survey data collected from substitute respondents. Am J Epidemiol 1977; 106: 476-484.

4. Marshall J, Priore R, Haughey B et al. Spouse-subject interviews and the reliability of diet studies. Am $\mathbf{J}$ Epidemiol 1980; 112: 675-683.

5. Lerchen ML, Samet JM. An assessment of the validity of questionnaire responses provided by a surviving spouse. Am J Epidemiol 1986; 123: 481-489.

6. Humble CG, Samet JM, Skipper BE. Comparison of self- and surrogate-reported dietary information. Am J Epidemiol 1984; 119: 86-98.
7. Napier JA, Johnson BJ, Epstein FH. The Tecumseh, Michigan Community Health Study. In: Kessler II, Levin ML, Eds. The Community as an Epidemiologic Laboratory. A Casebook of Community Studies. Baltimore, Md: The Johns Hopkins Press; 1970: 25-44.

8. Thompson FE, Lamphiear DE, Metzner HL et al. Reproducibility of reports of frequency of food use in the Tecumseh Diet Methodolngy Study. Am J Epidemiol 1987; 125: 658-671.

9. Fleiss JL, Cohen J. The equivalence of weighted kappa and the intraclass correlation coefficient as measures of reliability. Educ Psychol Meas 1973; 33: 613-619.

10. Rogot E, Reid DD. The validity of data from next-ofkin in studies of mortality among migrants. Int $\mathbf{J}$ Epidemiol 1975; 4: 51-54.

11. Herrmann N. Retrospective information from questionnaires. 1. Comparability of primary respondents and their next-of-kin. Am J Epidemiol 1985; 121: 937-947.

12. Block G. A review of dietary assessment methods. Am J Epidemiol 1982; 115: 492-504. 